\title{
DAB2IP Expression in Abdominal Aortic Aneurysm: EZH2 and mir-363-3p as Potential Mediators
}

\author{
EVANGELIA LEGAKI $^{1}$, CHRISTOS KLONARIS $^{2}$, DIMITRIOS ATHANASIADIS ${ }^{2}$, \\ NIKOLAOS PATELIS ${ }^{2}$, ANNA SIOZIOU ${ }^{1}$, THEODOROS LIAKAKOS $^{2}$ and MARIA GAZOULI ${ }^{1}$ \\ ${ }^{1}$ Department of Basic Medical Sciences, Laboratory of Biology, Medical School, \\ National and Kapodistrian University of Athens, Athens, Greece; \\ ${ }^{2}$ First Department of Surgery, Vascular Unit, National and Kapodistrian University of Athens, \\ Laiko General Hospital, Athens, Greece
}

\begin{abstract}
Background/Aim: Nine genetic loci have been associated with abdominal aortic aneurysm (AAA) susceptibility, including DAB2IP. This gene is playing a role in apoptosis, cell proliferation and epithelial-tomesenchymal transition in cancers. This study aimed to elucidate the differential expression levels of DAB2IP in AAA tissues and investigate whether mir-363-3p and EZH2 can be considered as potential mediators of its expression. Materials and Methods: 18 AAA samples and 15 nonaneurysmatic controls were collected. Relative $m R N A$ expression levels of DAB2IP, EZH2 and mir-363-3p were measured using qPCR. Results: DAB2IP was significant upregulated ( 2.29 fold) in AAA tissues, while EZH2 and mir363-3p were down-regulated $(3.28$ and 3.62-fold, respectively). A limited negative correlation was found between the DAB2IP and EZH2 expression and between DAB2IP and the mir-363-3p. Conclusion: An increased expression of DAB2IP in AAA tissues was shown. We suggest 2 potential mediators of DAB2IP expression in abdominal aortic aneurysm, EZH2 and mir-363-3p.
\end{abstract}

Abdominal aortic aneurysm (AAA) is a degenerative condition defined as a permanent localized pathological dilation of the aorta more than 50\% compared to another site along the aorta, or an aortic diameter exceeding $30 \mathrm{~mm}$.

This article is freely accessible online.

Correspondence to: Maria Gazouli, Department of Basic Medical Sciences, Laboratory of Biology, Medical School, National and Kapodistrian University of Athens, Athens, Greece, Michalakopoulou 176, 11527 Athens, Greece. Tel: +30 2107462231, e-mail: mgazouli@med.uoa.gr

Key Words: Abdominal aortic aneurysm (AAA), Disabled homolog 2-interacting protein (DAB2IP), miR-363-3p, EZH2.
AAA is a common disease, often asymptomatic and it was discovered accidentally in imaging studies. If left untreated, AAA can rupture at advanced stages leading to high morbidity and mortality rates (1-3).

Nowadays, the prevalence of AAA ranges between $1.7-4.5 \%$ in men versus $0.5-1.3 \%$ in women, showing the highest prevalence in ages of 65-74 years (4-6). It is a complex, multifactorial disease influenced by genetic and environmental risk factors, with smoking, coronary artery disease and family history being the main contributors $(7,8)$. The pathogenesis of AAA is a result of several biological processes and involves all vascular cell subtypes. From the histological perspective, inflammation, extracellular matrix degradation, vascular smooth muscle cells (SMCs) apoptosis and increased oxidative stress are key mechanisms involved in the development of AAA $(3,9)$. To date, pharmacological treatment cannot prevent further progression of the disease or rupture without significant side-effects (3). The only available treatment option is the endovascular or open repair of the lesion; however, patients still face the operative risk. Candidates for this operation are patients with $A A A \geq 55 \mathrm{~mm}$, while smaller ones cannot benefit from any treatment $(3,10)$. Therefore, a better understanding of the genetic mechanisms contributing to the disease could open the way for novel, nonsurgical approaches.

Evidence suggests that genetics contribute to the development of AAA $(10,11)$. Previous genome-wide associations studies (GWAS) have indicated six highly implicated chromosomal regions for high AAA risk: i) Disabled homolog 2-interacting protein interactive protein (DAB2IP), ii) low density lipoprotein receptor-related protein 1 (LRP1), iii) CDKN2BAS, iv) low-density lipoprotein receptor (LDLR), v) sortilin 1 (SORT1) and vi) interleukin 6 (IL-6) (12-15). Recently, a meta- analysis added 4 disease specific loci: i) matrix Metalloproteinase-9 (MMP9), ii) long intergenic non-protein coding RNA 540 (LINC00540), iii) ETS-related gene (ERG), and iv) SET and MYND domain-containing 2 (SMYD2) (14). 
Gretarsdottir et al., have identified an association between the rs7025486 in DAB2IP and abdominal aortic aneurysm, a single nuclear polymorphism (SNP), which is also associated with coronary artery disease, peripheral arterial disease, venous thromboembolism, and pulmonary embolism (16). DAB2IP is a member of the RAS-GTPase activating protein family located on human chromosome 9q33.1-q33.3. DAB2IP has been implicated in various biological processes including proliferation, apoptosis, epithelial-to-mesenchymal transition (EMT), cancer stem cell (CSC) and autophagy (17). The role of DAB2IP has been extensively described in different cancers; however its exact role in abdominal aortic aneurysm still remains unknown. DAB2IP implication in promoting apoptosis and suppressing cell survival and proliferation via PI3-Akt and ASK1-JNK-MAPK pathways make it as a plausible candidate gene for AAA pathobiology $(7,18)$. DAB2IP has also been referred as an endogenous inhibitor of VEGFR2-mediated signaling, an important regulator of angio-genesis (19).

DAB2IP expression, which is strongly down-regulated in most types of cancer, is epigenetically suppressed by EZH2, a histone methyltransferase that forms part of the polycomb repressor complex. An inverse correlation between $E Z H 2$ and $h D A B 2 I P$ gene expression has been mentioned in $\mathrm{PCa}$ and medulloblastoma cells. The EZH2 appears to be a transcription repressor that is involved with the cellular memory system, X-inactivation, germline development, stem cell pluripotency and cancer metastasis $(20,21)$.

MiRNAs are also important gene expression regulators. They are small single-stranded molecules, 20-23 nucleotides long, that regulate gene expression by inhibiting translation or by leading their targets (mRNAs) to degradation (22). According to the databases "mirdb.org" and "Target Scan Human 7.2", mir-363-3p is a potential regulator of DAB2IP expression.

To the best of our knowledge there are only few data about DAB2IP expression in abdominal aortic aneurysm. Therefore, this study aims to elucidate the differential expression of $D A B 2 I P$ in abdominal aortic aneurysm tissues and to investigate potential mediators of its expression, such as mir-363-3p and EZH2.

\section{Materials and Methods}

Collection of specimens. Over the period of two years, full-thickness aortic tissue samples were collected from the anterior section of the point of maximum diameter of the intrarenal aorta of patients $(n=18)$ undergoing open AAA repair. The patients who participated in the study (2 females, 16 males) were hospitalized at the First Department of Surgery at Laiko General Hospital of Athens (Greece) and their mean age was 71.8 \pm 8.23 . AAA specimens were transferred and stored at $-80^{\circ} \mathrm{C}$ at the Biology Laboratory of the Athens School of Medicine. When technically feasible and without jeopardizing the technical success of the procedure and the expected patient outcomes, non-aneurysmatic aortic samples of the aneurysm neck were also collected for use as controls $(n=15)$. All participants provided written informed consent before entering the study. The
Table I. Demographics and clinical characteristics of patients participate in our study.

\begin{tabular}{lc}
\hline Parameter & Value (n=18) \\
\hline Gender (F/M) & $2 / 16$ \\
Age (mean \pm SEM, years) & $71.8 \pm 8.23$ \\
Smoking & $16(88.8 \%)$ \\
Diabetes (\%) & $3(16.6 \%)$ \\
Hypertension (\%) & $15(83.3 \%)$ \\
Cholesterol (\%) & $6(33.3 \%)$ \\
Triglycerides (\%) & $5(27.8 \%)$ \\
Coronary artery disease (\%) & $4(22.2 \%)$ \\
Chronic obstructive pulmonary disease (\%) & $7(38.9 \%)$ \\
Chronic kidney disease (\%) & $3(16.7 \%)$ \\
Statin therapy & $6(33.3 \%)$ \\
Antiplatelet drugs $(\%)$ & $8(44.4 \%)$ \\
\hline
\end{tabular}

study was conducted in accordance with the Declaration of Helsinki and was approved by our Hospital's Ethics committee. Table I shows the data concerning the demographic and clinical parameters of our patients.

RNA Extraction and Quantitative Real Time PCR. Total RNA was extracted using the TRIzol ${ }^{\circledR}$ (Invitrogen, Waltham, MA, USA) method followed by cDNA synthesis using the PrimeScript RT Reagent Kit -Perfect Real Time (Takara Bio Europe, Saint-Germainen-Laye, France) in the SC300 SuperCycler- Thermal Cycler (Kyratec, Queensland, Australia). SYBR Green real time PCR (KAPA SYBR FAST qPCR Master Mix - Kapa Biosystems (Wilmington, MA,USA) was performed in a Sa-Cycler 96 Real Time PCR System (Sacace Biostechnologies, Como, Italy) to identify DAB2IP, and mir363-3p expression by employing the glyceraldehyde-3-phosphatedehydrogenase $(G A P D H)$ and U6snRNA expression levels as internal controls (reference genes). The primers sequences (Forward: F and Reverse: R) were specific for each gene and miRNA as follows: DAB2IP F: 5'-CCTGGACGATGTGCTCTATG-3'; DAB2IP R: 5'TCTTCTTCTTCTTGTCGGTCTC-3'; EZH2 F: 5'-AATCAG AGTACATGCGACTGAGA-3'; EZH2 R: 5'-GCTGTATCCTTC GCTGTTTCC-3'; Mir-363-3p F: 5'-ACACTCCAGCTGGGGAA TTGCACGGTATCCA-3'; Mir-363-3p R: 5'-TGGTGTCGTGG AGTCG-3'; GAPDH F: 5'-CATCTCTGCCCC CTCTGCTG-3'; GAPDH R: 5'-GCCTGCTTCACCACCTTCTTG-3'; U6snRNA F: 5'ATTGCAACGATACAGAGAAGATT-3'; U6snRNA R: 5'-GGA ACGCTTCACGAATTTG-3'

The experiment was performed in duplicates. Differentiation between gene expression in AAA and control tissues was measured as a fold change.

Statistical analysis. GraphPad Prism software (version 6.0) was used. Results with probability values less than $0.05(p<0.05)$ were classified as statistically significant. An independent-samples $t$-test was used to investigate the statistical difference in relative expressions of $D A B 2 I P, E Z H 2$ and mir-363-3p between AAA and control groups. A Pearson correlation coefficient was calculated to assess the correlation between a) DAB2IP mir-363-3p and b) DAB2IP and EZH2. Chisquare test was used for the comparison of demographic and clinical characteristic in cases and controls, as appropriate. 


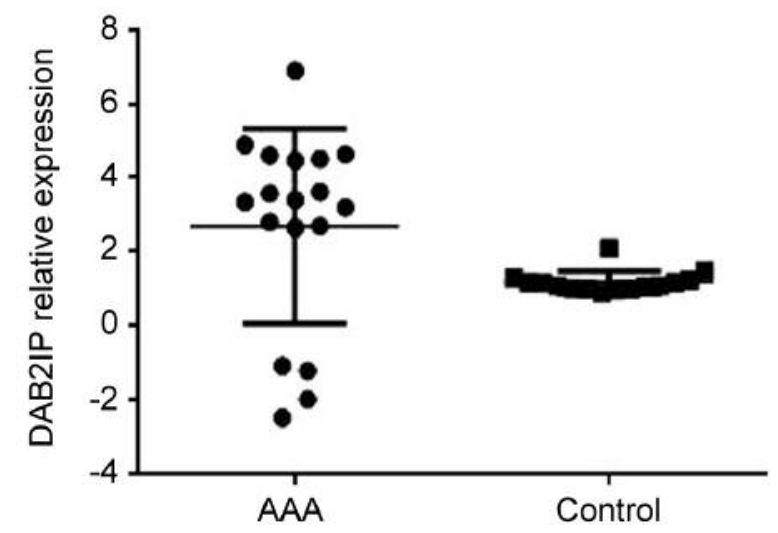

Figure 1. Analysis of the DAB2IP mRNA expression in abdominal aortic aneurysm (AAA) and control aortic tissues by real time quantitative RT-PCR. Statistical analysis showed increased mRNA expression level between AAA $(n=18,2.692 \pm 0.62)$ and control aortic tissues $(n=15$, $1.175 \pm 0.077$ ), with $p<0.05$.

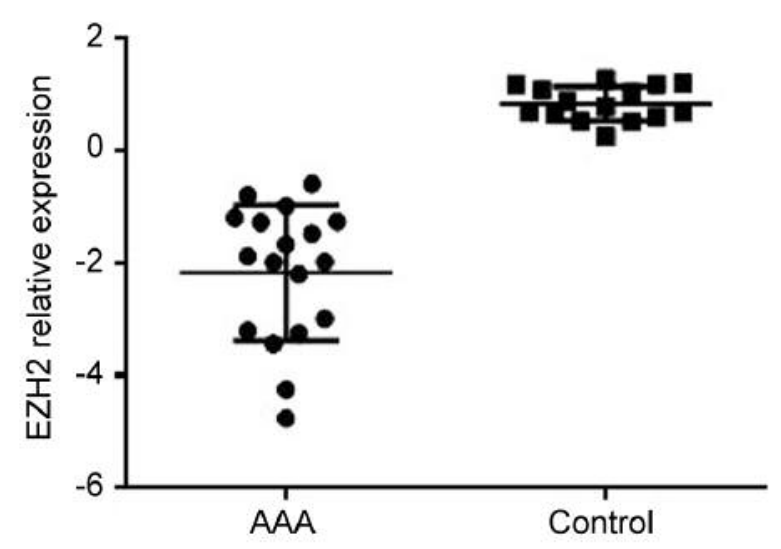

Figure 2. Analysis of the EZH2 mRNA expression in abdominal aortic aneurysm (AAA) and control aortic tissues by real time quantitative $R T$ PCR. A lower mRNA expression level was observed between AAA $(n=18,-2.178 \pm 0.284)$ and non aneurysmatic aortic tissues $(n=15$, $0.8307 \pm 0.079$ ), with $p<0.0005$.

\section{Results}

Samples from 18 patients with abdominal aortic aneurysm were studied. Non-aneurysmatic adjacent regions of 15 samples were used as controls. We first analyzed the levels of DAB2IP mRNA and compared them between AAA tissues and controls. An approximately 2.29-fold significant $(p<0.05)$ increase was observed in the DAB2IP relative expression in AAA $(\mathrm{n}=18,2.692 \pm 0.62)$ compared to the controls $(n=15,1.175 \pm 0.077)$ (Figure 1). In order to investigate possible mediators of DAB2IP expression we continued with the EZH2 expression analysis. Our results presented a highly significant $(p<0.0001)$, approximately

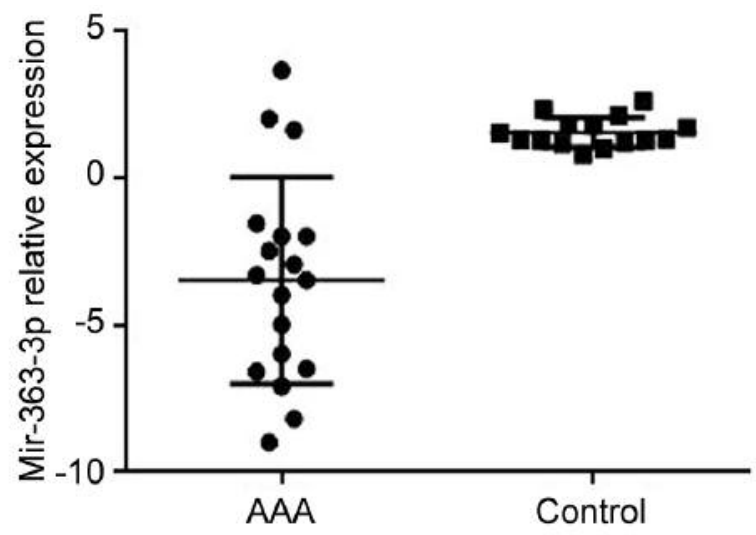

Figure 3. Analysis of the relative expression of mir-363p in human abdominal aortic tissues (AAA, $n=18)$ and control aortic tissues $(n=15)$ by real time quantitative RT-PCR. miR-363-3p was significantly downregulated $(p<0.0005)$ in AAA tissues $(n=18,-3.494 \pm 0.828)$ compared to controls (1.536 \pm 0.1313$)$.

3.62 fold reduction in the $E Z H 2$ relative expression in AAA $(\mathrm{n}=18,-2.178 \pm 0.284)$ compared to the controls $(\mathrm{n}=15$, $0.8307 \pm 0.079$ ) (Figure 2). Mir-363-3p is another possible gene regulator, as it targets $D A B 2 I P$. We measured mir-363$3 \mathrm{p}$ relative expression in AAA samples $(\mathrm{n}=18,-3.494 \pm 0.828)$ and controls $(n=15,1.536 \pm 0.1313)$ and we found an extremely significant reduction, approximately 3.28 fold $(p<0.0001)$ (Figure 3). The significantly increased DAB2IP relative expression and the significantly lower expression of EZH2 and mir-363-3p led us to examine the correlation between $D A B 2 I P$ expression and each mediator through Pearson correlation coefficient (Figure 4). This analysis indicated a limited negative correlation between the DAB2IP and EZH2 expression levels $(\mathrm{r}=-0.45, p<0.05)$. Similar limited negative correlation was observed between the $D A B 2 I P$ and the mir-363-3p ( $\mathrm{r}=-0.40, p<0.05)$.

\section{Discussion}

AAA is a life threatening, complex, multifactorial disease influenced by genetic and environmental risk factors (7). The pathogenesis of AAA is a result of several biological processes with inflammation, extracellular matrix degradation and vascular smooth muscle cell apoptosis being the majors (23). DAB2IP has been widely known to play an important role in many cancers, including prostate, lung, gastrointestinal and breast cancer (25-27).

$D A B 2 I P$ is a tumour suppressor gene involved in cell signalling, survival, migration, maturation, and apoptosis. In vitro functional studies have demonstrated that loss of its protein product leads to enhanced cell proliferation and reduced apoptosis via the PI3-Akt pathway and ASK1 pathways (18). During the past decade, studies have associated 


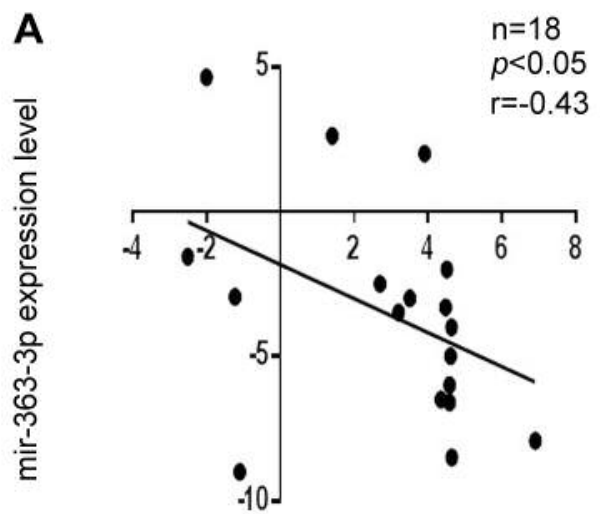

DAB2IP expression level

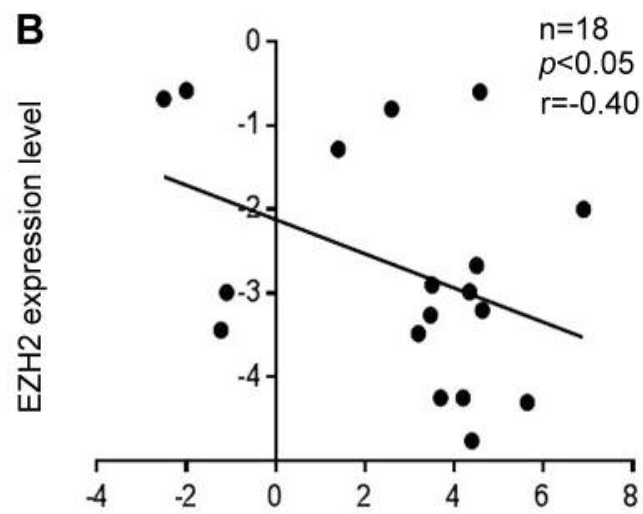

DAB2IP expression level

Figure 4. Analysis of the correlation between DAB2IP expression and the expression of (A) miR-363-3p and B) EZH2, through Pearson correlation coefficient. A limited negative correlation was observed between the DAB2IP and both EZH2 $(r=-0.45, p<0.05)$ and miR-363-3p expression levels $(r=-0.40, p<0.05)$.

$D A B 2 I P$ with the development of abdominal aortic aneurysm. A GWAS study by Gretarsdottir et al., have identified a sequence variant (rs7025486) within the DAB2IP gene, which confers susceptibility to abdominal aortic aneurysm (16). This polymorphism was also confirmed as a risk locus by strong evidence for abdominal aortic aneurysm in a recent metaanalysis (28). A further meta-analysis by Jones et al., has revealed that another SNP, the rs10985349, is also associated with abdominal aortic aneurysm susceptibility (14).

To the best of our knowledge, there is only one study concerning DAB2IP expression, despite the strong correlation of these 2 loci to abdominal aortic aneurysm risk. Lenk et al., have concluded that $D A B 2 I P$ expression is significantly reduced in AAA tissues compared to controls, using a whole-genome expression chip on 13 individual RNA samples and 2 pooled RNA samples (29).

Our study examined DAB2IP expression in 18 AAA samples and compared it to expression from 15 controls. Contrary to Lenk et al., our results showed a significant increase, approximately 2.75 -fold, of $D A B 2 I P$ relative expression in pathological tissues compared to non aneurysmatic. This up-regulation could be associated with abdominal aortic aneurysm as an elevated DAB2IP expression may lead to an increase in vascular smooth muscle cells apoptosis $(18,30)$.

Interestingly, in cancer, $D A B 2 I P$ expression is modulated by $\mathrm{EZH} 2$, a histone methyltransferase forms part of the polycomb repressor complex $(31,32)$. A significant negative correlation between overexpressed $E Z H 2$ and down-regulated $D A B 2 I P$ has been reported in prostate and medulloblastoma cancer. $D A B 2 I P$ suppression in medulloblastoma cells can be, at least partly, reversed by $E Z H 2$ inhibition, thus it has been proposed as a potential drug target $(20,21)$.
In this study, the evaluation of EZH2 relative expression showed a 2.17-fold down-regulation in aortic tissues compared to controls. A further statistical analysis indicated a limited negative correlation between EZH2 and DAB2IP expression confirming their inverse relationship in abdominal aortic aneurysm in addition to cancer $(20,21)$.

MiRNAs are a class of RNAs that negatively regulate gene expression (33). Experiments with specific SMCs emphasize the importance of miRNAs for homeostasis of vascular SMCs (34), and it is likely that miRNAs also play a role in aneurysm formation, which is characterized by dysfunction of vascular SMCs (35). Using various miRNA prediction databases and focusing on miRNAs which potentially target $D A B 2 I P$, we measured the expression of mir-363-3p in order to reveal other mediators of $D A B 2 I P$ expression in abdominal aortic aneurysm. Mir-363-3p has been associated with prostate cancer and the interaction with DAB2IP has been implicated in the suppression of epithelial-to-mesenchymal transition (36). EMT disturbance has been referred to play a role in numerous chronic cardiovascular disease states such as heart failure and pulmonary hypertension and various forms of chronic vasculopathy (37).

According to our findings, mir-363-3p was significantly down-regulated in AAA tissues compared to controls, while Pearson's correlation revealed a limited negative correlation between DAB2IP expression and this miRNA.

In conclusion, our study reveals an elevated expression of DAB2IP which could be modulated via the parallel downregulation of EZH2 and mir-363-3p. Different pathways may be involved, such as increased apoptosis or disturbed EMT. By understanding the pathophysiology of aneurysm formation, treatments targeting certain molecules can be designed to interrupt the growth or prevent the rupture of the 
aneurysm. If the link between DAB2IP expression and its mediators is clarified, molecules, such as EZH2 and mir-363$3 p$ could also be potential therapeutic targets which will reduce AAA formation.

\section{Conflicts of Interest}

None.

\section{Author's Contributions}

EL, MG and CK conceived of the presented idea. MG designed the study. EL and AS performed the experiments. EL wrote the article with support from MG, CK, and TL. DA, NP contributed to data and samples collection. EL, AS, MG contributed to the interpretation of the results. MG, CK and TL made the critical revision of the article and the final approval of the version to be published.

\section{Acknowledgments}

This research work was supported by the Hellenic Foundation for Research and Innovation (HFRI) and the General Secretariat for Research and Technology (GSRT), under the HFRI PhD Fellowship grant (GA. 14493).

\section{References}

1 Aggarwal S, Qamar A, Sharma V and Sharma A: Abdominal aortic aneurysm: A comprehensive review. Exp Clin Cardiol 16(1): 11-5, 2011. PMID: 21523201.

2 Groeneveld ME, Meekel JP, Rubinstein SM, Merkestein LR, Tangelder GJ, Wisselink W, Truijers $M$ and Yeung KK: Systematic review of circulating, biomechanical, and genetic markers for the prediction of abdominal aortic aneurysm growth and rupture. Am Heart Assoc 30: 7(13), 2018. PMID: 29960996. DOI: 10.1161/JAHA.117.007791

3 Kuivaniemi H, Ryer EJ, Elmore JR and Tromp G: Understanding the pathogenesis of abdominal aortic aneurysms. Expert Rev Cardiovasc Ther 13(9): 975-987, 2015. PMID: 26308600. DOI: $10.1586 / 14779072.2015 .1074861$

4 Sidloff D, Stather P, Dattani N, Bown M, Thompson J, Sayers $\mathrm{R}$ and Choke E: Aneurysm global epidemiology study: public health measures can further reduce abdominal aortic aneurysm mortality. Circulation 129(7): 747-753, 2014. PMID: 24249717. DOI: 10.1161/CIRCULATIONAHA.113.005457

5 Lo RC and Schermerhorn ML: Abdominal aortic aneurysms in women. J Vasc Surg 63(3): 839-844, 2016. PMID: 26747679. DOI: $10.1016 /$ j.jvs.2015.10.087

6 Li X, Zhao G, Zhang J, Duan Z and Xin S: Prevalence and trends of the abdominal aortic aneurysms epidemic in general population--a meta-analysis. PLoS One 8(12): e81260, 2013. PMID: 24312543. DOI: 10.1371/journal.pone.0081260

7 Golledge $\mathrm{J}$ and Kuivaniemi H: Genetics of abdominal aortic aneurysm. Curr Opin Cardiol 28(3): 290-296, 2013. PMID: 23478885. DOI: $10.1097 / \mathrm{HCO} .0 \mathrm{~b} 013 \mathrm{e} 32835$ f0d55

8 Ullery BW, Hallett RL and Fleischmann D: Epidemiology and contemporary management of abdominal aortic aneurysms. Abdom Radiol (NY) 43(5): 1032-1043, 2018. PMID:29313113. DOI: $10.1007 / \mathrm{s} 00261-017-1450-7$
9 Maegdefessel L, Dalman RL and Tsao PS: Pathogenesis of abdominal aortic aneurysms: microRNAs, proteases, genetic associations. Annu Rev Med 65: 49-62, 2014. PMID: 24274177. DOI: 10.1146/annurev-med-101712-174206

10 Harrison SC, Kalea AZ, Holmes MV, Agu O and Humphries SE: Genomic research to identify novel pathways in the development of abdominal aortic aneurysm. Cardiol Res Pract 2012: 852829, 2012. PMID: 22400124. DOI: 10.1155/2012/852829

11 Pahl MC, Derr K, Gäbel G, Hinterseher I, Elmore JR, Schworer CM, Peeler TC, Franklin DP, Gray JL, Carey DJ, Tromp G and Kuivaniemi H: MicroRNA expression signature in human abdominal aortic aneurysms. BMC Med Genomics 5: 25, 2012. PMID: 22704053. DOI: 10.1186/1755-8794-5-25

12 Miner GH, Costa KD, Hanss BG and Marin ML: An evolving understanding of the genetic causes of abdominal aortic aneurysm disease. Surg Technol Int 26: 197-205, 2015. PMID: 26055010.

13 Davis FM, Rateri DL and Daugherty A: Abdominal aortic aneurysm: novel mechanisms and therapies. Curr Opin Cardiol 30(6): 566-573, 2015. PMID: 26352243. DOI: 10.1097/HCO.00 00000000000216

14 Jones GT, Tromp G, Kuivaniemi H, Gretarsdottir S, Baas AF, Giusti B, Strauss E, Van't Hof FN, Webb TR, Erdman R, Ritchie MD, Elmore JR, Verma A, Pendergrass S, Kullo IJ, Ye Z, Peissig PL, Gottesman O, Verma SS, Malinowski J, Rasmussen-Torvik LJ, Borthwick KM, Smelser DT, Crosslin DR, de Andrade M, Ryer EJ, McCarty CA, Böttinger EP, Pacheco JA, Crawford DC, Carrell DS, Gerhard GS, Franklin DP, Carey DJ, Phillips VL, Williams MJ, Wei W, Blair R, Hill AA, Vasudevan TM, Lewis DR, Thomson IA, Krysa J, Hill GB, Roake J, Merriman TR, Oszkinis G, Galora S, Saracini C, Abbate R, Pulli R, Pratesi C, Saratzis A, Verissimo AR, Bumpstead S, Badger SA, Clough RE, Cockerill G, Hafez H, Scott DJ, Futers TS, Romaine SP, Bridge K, Griffin KJ, Bailey MA, Smith A, Thompson MM, van Bockxmeer FM, Matthiasson SE, Thorleifsson G, Thorsteinsdottir U, Blankensteijn JD, Teijink JA, Wijmenga C, de Graaf J, Kiemeney LA, Lindholt JS, Hughes A, Bradley DT, Stirrups K, Golledge J, Norman PE, Powell JT, Humphries SE, Hamby SE, Goodall AH, Nelson CP, Sakalihasan N, Courtois A, Ferrell RE, Eriksson P, Folkersen L, FrancoCereceda A, Eicher JD, Johnson AD, Betsholtz C, Ruusalepp A, Franzén O, Schadt EE, Björkegren JL, Lipovich L, Drolet AM, Verhoeven EL, Zeebregts CJ, Geelkerken RH, van Sambeek MR, van Sterkenburg SM, de Vries JP, Stefansson K, Thompson JR, de Bakker PI, Deloukas P, Sayers RD, Harrison SC, van Rij AM, Samani NJ and Bown MJ: Meta-Analysis of Genome-Wide Association Studies for Abdominal Aortic Aneurysm Identifies Four New Disease-Specific Risk Loci. Circ Res 120(2): 341-353, 2017. PMID: 27899403. DOI: 10.1161/CIRCRESAHA.116.308765

15 Bown MJ: Genomic insights into abdominal aortic aneurysms. Ann R Coll Surg Engl 96(6): 405-14, 2014. PMID: 25198969. DOI: 10.1308/003588414X13946184901560

16 Gretarsdottir S, Baas AF, Thorleifsson G, Holm H, den Heijer M, de Vries J P, Kranendonk SF, Kranendonk SE, Zeebregts CJ, van Sterkenburg SM, Geelkerken RH, van Rij AM, Williams MJ, Boll AP, Kostic JP, Jonasdottir A, Jonasdottir A, Walters GB, Masson G, Sulem P, Saemundsdottir J, Mouy M, Magnusson KP, Tromp G, Elmore JR, Sakalihasan N, Limet R, Defraigne JO, Ferrell RE, Ronkainen A, Ruigrok YM, Wijmenga C, Grobbee DE, Shah SH, Granger CB, Quyyumi AA, Vaccarino V, Patel RS, Zafari AM, Levey AI, Austin H, Girelli D, Pignatti PF, Olivieri O, Martinelli N, Malerba G, Trabetti E, Becker LC, Becker DM, Reilly MP, 
Rader DJ, Mueller T, Dieplinger B, Haltmayer M, Urbonavicius S, Lindblad B, Gottsäter A, Gaetani E, Pola R, Wells P, Rodger M, Forgie M, Langlois N, Corral J, Vicente V, Fontcuberta J, España F, Grarup N, Jørgensen T, Witte DR, Hansen T, Pedersen O, Aben KK, de Graaf J, Holewijn S, Folkersen L, Franco-Cereceda A, Eriksson P, Collier DA, Stefansson H, Steinthorsdottir V, Rafnar T, Valdimarsson EM, Magnadottir HB, Sveinbjornsdottir S, Olafsson I, Magnusson MK, Palmason R, Haraldsdottir V, Andersen K, Onundarson PT, Thorgeirsson G, Kiemeney LA, Powell JT, Carey DJ, Kuivaniemi H, Lindholt JS, Jones GT, Kong A, Blankensteijn JD, Matthiasson SE, Thorsteinsdottir U and Stefansson K: Genomewide association study identifies a sequence variant within the DAB2IP gene conferring susceptibility to abdominal aortic aneurysm. Nat genet 42(8): 692-697, 2010. DOI: 10.1038/ng.622

17 Liu L, Xu C, Hsieh JT, Gong J and Xie D: DAB2IP in cancer. Oncotarget 7(4): 3766-3776, 2016. PMID: 26658103. DOI: 10.18632 /oncotarget.6501

18 Xie D, Gore C, Zhou J, Pong RC, Zhang H, Yu L, Vessella RL, Min W and Hsieh JT: DAB2IP coordinates both PI3K-Akt and ASK1 pathways for cell survival and apoptosis. Proc Natl Acad Sci US 106(47): 19878-19883, 2009. PMID: 19903888. DOI: 10.1073/pnas.0908458106

19 Zhang H, He Y, Dai S, Xu Z, Luo Y, Wan T, Luo D, Jones D, Tang S, Chen H, Sessa WC and Min W: AIP1 functions as an endogenous inhibitor of VEGFR2-mediated signaling and inflammatory angiogenesis in mice. J Clin Invest 118: 39043916, 2008. PMID: 19033661. DOI: $10.1172 / \mathrm{JCI} 36168$

20 Chen H, Tu SW and Hsieh JT: Down-regulation of human DAB2IP gene expression mediated by polycomb Ezh2 complex and histone deacetylase in prostate cancer. J Biol Chem 280(23): 22437-22444, 2005. PMID: 15817459 . DOI: $10.1074 /$ jbc.M501379200

21 Smits M, van Rijn S, Hulleman E, Biesmans D, van Vuurden DG, Kool M and Haberler C: EZH2-regulated DAB2IP is a medulloblastoma tumor suppressor and a positive marker for survival. Clin Cancer Res 18(15): 4048-4058, 2012. PMID: 22696229. DOI: 10.1158/1078-0432.CCR-12-0399

22 Winter J, Jung S, Keller S, Gregory RI and Diederichs S: Many roads to maturity: microRNA biogenesis pathways and their regulation. Nat Cell Biol 11(3): 228-234, 2009. PMID: 19255566. DOI: $10.1038 /$ ncb0309-228

23 Nordon IM, Hinchliffe RJ, Loftus IM and Thompson MM: Pathophysiology and epidemiology of abdominal aortic aneurysms. Nat Rev Cardiol 8(2): 92-102, 2011. PMID: 21079638. DOI: $10.1038 /$ nrcardio.2010.180

24 Dote H, Toyooka S, Tsukuda K, Yano M, Ota T, Naito M, Toyota M, Gazdar AF and Shimizu N: Aberrant promoter methylation in human DAB2 interactive protein (hDAB2IP) gene in gastrointestinal tumour. Br J Cancer 92: 1117-1125, 2005. PMID: 15770214. DOI: 10.1038/sj.bjc.6602458

25 Dote H, Toyooka S, Tsukuda K, Yano M, Ouchida M, Doihara H, Suzuki M, Chen H, Hsieh JT, Gazdar AF and Shimizu N: Aberrant promoter methylation in human DAB2 interactive protein (h DAB2IP) gene in breast cancer. Clin Cancer Res 10: 2082-2089, 2004. PMID: 15041729.

26 Qiu GH, Xie HM, Wheelhouse N, Harrison D, Chen GG, SaltoTellez M, Lai P, Ross JA and Hooi SC: Differential expression of hDAB2IPA and hDAB2IPB in normal tissues and promoter methylation of hDAB2IPA in hepatocellular carcinoma. J Hepatol 46: 655-663, 2007. PMID: 17258345. DOI: 10.1016/ j.jhep.2006.11.012
27 Xie DX, Gore C, Liu J, Pong RC, Mason R, Hao GY, Long M, Kabbani W, Yu L, Zhang H, Chen H, Sun X, Boothman DA, Min W and Hsieh JT: Role of DAB2IP in modulating epithelialto-mesenchymal transition and prostate cancer metastasis. Proc Natl Acad Sci USA 107: 2485-2490, 2010. PMID: 20080667. DOI: 10.1073/pnas.0908133107

28 Bradley DT, Badger SA, McFarland $M$ and Hughes AE: Abdominal Aortic Aneurysm Genetic Associations: Mostly False? A Systematic Review and Meta-analysis. Eur J Vasc Endovasc Surg 51(1): 64-75, 2016. PMID: 26460285. DOI: 10.1016/j.ejvs.2015.09.006

29 Lenk GM, Tromp G, Weinsheimer S, Gatalica Z, Berguer R and Kuivaniemi $\mathrm{H}$ : Whole genome expression profiling reveals a significant role for immune function in human abdominal aortic aneurysms. BMC Genomics 8: 237, 2007. PMID: 17634102. DOI: $10.1186 / 1471-2164-8-237$

$30 \mathrm{Yu}$ L, Qin L, Zhang H, He Y, Chen H, Pober JS, Tellides G and Min W: AIP1 prevents graft arteriosclerosis by inhibiting interferon- $\gamma$-dependent smooth muscle cell proliferation and intimal expansion. Circ Res 109(4): 418-427, 2011. PMID: 21700930. DOI:10.1161/CIRCRESAHA.111.248245

31 Simon JA and Lange CA: Roles of the EZH2 histone methyltransferase in cancer epigenetics. Mutat Res 647(1-2): 2129, 2008. PMID: 18723033. DOI: 10.1016/j.mrfmmm.2008.07.010

32 Min J, Zaslavsky A, Fedele G, McLaughlin SK, Reczek EE, De Raedt T, Guney I, Strochlic DE, Macconaill LE, Beroukhim R, Bronson RT, Ryeom S, Hahn WC, Loda M and Cichowski K: An oncogene-tumor suppressor cascade drives metastatic prostate cancer by coordinately activating Ras and nuclear factor-kappa B. J Nat Med 16(3): 286-294, 2010. PMID: 20154697. DOI: 10.1038/nm.2100

33 Bartel DP: MicroRNAs: target recognition and regulatory functions. Cell 136: 215-233, 2009. PMID:19167326. DOI: 10.1016/j.cell.2009.01.002

34 Albinsson S, Suarez Y, Skoura A, Offermanns S, Miano JM and Sessa WC: MicroRNAs are necessary for vascular smooth muscle growth, differentiation, and function. Arterioscler Thromb Vasc Biol 30(6): 1118-1126, 2010. PMID: 20378849. DOI: 10.1161/ATVBAHA.109.200873

35 Joviliano EE, Ribeiro MS and Tenorio EJR: MicroRNAs and current concepts on the pathogenesis of abdominal aortic aneurysm. Braz J Cardiovasc Surg 32(3): 215-224, 2017. PMID: 28832801. DOI: 10.21470/1678-9741-2016-0050

36 Lo UG, Pong RC, Yang D, Gandee L, Hernandez E, Dang A, Lin CJ, Santoyo J, Ma S, Sonavane R, Huang J, Tseng SF, Moro L, Arbini AA, Kapur P, Raj GV, He D, Lai CH, Lin H and Hsieh JT: IFN-r-induced IFIT5 promotes epithelial-to-mesenchymal transition in prostate cancer via microRNA processing. Cancer research 2207, 2018. PMID: 30504123. DOI: 10.1158/00085472.CAN-18-2207

37 Kovacic JC, Mercader N, Torres M, Boehm M and Fuster V: Epithelial-to-mesenchymal and endothelial-to-mesenchymal transition: from cardiovascular development to disease. Circulation 125(14): 1795-1808, 2012. PMID: 22492947. DOI: 10.1161/CIRCULATIONAHA.111.040352

Received February 19, 2019

Revised April 5, 2019

Accepted April 9, 2019 